\title{
Study of Lactic Acid Thermal Behavior Using Thermoanalytical Techniques
}

\author{
Andrea Komesu, ${ }^{1}$ Patricia Fazzio Martins Martinez, ${ }^{1}$ Betânia Hoss Lunelli, ${ }^{1}$ \\ Johnatt Oliveira, ${ }^{2}$ Maria Regina Wolf Maciel, ${ }^{1}$ and Rubens Maciel Filho ${ }^{1}$ \\ ${ }^{1}$ School of Chemical Engineering, University of Campinas (UNICAMP), Department of Process and Product Development, \\ Av. Albert Einstein 500, 13083-970 Campinas, SP, Brazil \\ ${ }^{2}$ Institute of Health Sciences, Nutrition College, Federal University of Pará (UFPA), Augusto Corrêa St. 01, \\ 66073-040 Belém, PA, Brazil
}

Correspondence should be addressed to Andrea Komesu; andrea_komesu@hotmail.com

Received 2 March 2017; Accepted 4 April 2017; Published 18 April 2017

Academic Editor: Ewa Schab-Balcerzak

Copyright (C) 2017 Andrea Komesu et al. This is an open access article distributed under the Creative Commons Attribution License, which permits unrestricted use, distribution, and reproduction in any medium, provided the original work is properly cited.

\begin{abstract}
Actually, there is a growing interest in the biotechnological production of lactic acid by fermentation aiming to substitute fossil fuel routes. The development of an efficient method for its separation and purification from fermentation broth is very important to assure the economic viability of production. Due to its high reactivity and tendency to decompose at high temperatures, the study of lactic acid thermal behavior is essential for its separation processes and potential application. In the present study, differential scanning calorimetry (DSC) analyses showed endothermic peaks related to the process of evaporation. Data of thermogravimetry (TG/DTG) were correlated to Arrhenius and Kissinger equations to provide the evaporation kinetic parameters and used to determine the vaporization enthalpy. Activation energies were 51.08 and $48.37 \mathrm{~kJ} \cdot \mathrm{mol}^{-1}$ and frequency values were 859.97 and $968.81 \mathrm{~s}^{-1}$ obtained by Arrhenius and Kissinger equations, respectively. Thermogravimetry, coupled with mass spectroscopy (TGMS), provided useful information about decomposition products when lactic acid was heated at $573 \mathrm{~K}$ for approximately 30 min.
\end{abstract}

\section{Introduction}

Lactic acid or 2-hydroxypropionic acid, an organic acid manufactured by fermentation from renewable sources, such as corn, potato, and other agriculture products, is an alternative to conventional petroleum raw materials routes. It has a wide variety of applications, in cosmetics (moisturizers, skinlightening agents, skin-rejuvenating agents, $\mathrm{pH}$ regulators, antiacne agents, humectants, and antitartar agents), in pharmaceutical products (dialysis solution, mineral preparations, pills, prostheses, surgical sutures, and controlled drug delivery systems), in chemistry (descaling agents, $\mathrm{pH}$ regulators, neutralizers, chiral intermediates, green solvents, cleaning agents, slow acid release agents, and metal complexing agents), and in food (acidulants, preservatives, flavours, $\mathrm{pH}$ regulators, microbial quality improving agents, and mineral fortification) [1,2]. Furthermore, it is used as precursor of several other products, such as propylene oxide, acetaldehyde, acrylic acid, propionic acid, 2,3-pentanedione, ethyl lactate, and polylactic acid [3]; the latter is used for production of biodegradable polymers with medical applications. Over the last decade, more and more attention has been paid to its potential productivity due to its increasing demand in practice. However, it is still difficult to recover high quality lactic acid from a fermentation broth because of its characteristics such as high viscosity and thermal sensitivity [4].

The thermal sensitivity and high reactivity of lactic acid can be explained due the presence of two adjacent functional groups, acid and alcohol, in a small molecule with only three carbon atoms, as well as their tendency to decompose at high temperatures [5]. However, from literature review, no accurate study detailing the monomer lactic acid thermal behavior could be found. On the other hand, the polylactic acid (PLA), polymer produced by polymerization of lactic acid, has been extensively studied [6-10]. 
The development of an efficient method for separation and purification of carboxylic acids from fermentation broth is very important to allow its biotechnological production in commercial scale, since these steps are responsible for $30-40 \%$ of the total production costs [11]. However, for recovery and concentration of thermally unstable molecules, such as lactic acid, it is essential to understand how these molecules behave at high temperatures, which can be achieved through thermal analyses as differential scanning calorimetry (DSC), thermogravimetry (TG), and thermogravimetry coupled with mass spectroscopy (TG-MS).

DSC is performed by difference in energy supplied to the sample and the reference pan in function of temperature. By varying the energy of the sample as a function of temperature, physical and chemical phenomena can be observed. In general, phase transitions, dehydration, reduction, and decomposition reactions produce endothermic effects, whereas crystallization, oxidations, and some decomposition reactions produce exothermic effects [12]. DSC is often used because of its speed, simplicity, and availability [13]. Several reviews covering the fundamentals concepts, instrumentation, and general applications are available in the literature [13-16].

TG is a technique that records variation of mass while the sample is heated. The mass loss can be related to many phenomena such as dehydration, sublimation, evaporation, and decomposition. TG has been used to estimate the kinetic parameters, such as activation energies, reaction orders, and the Arrhenius preexponential factor, of degradation [17] and evaporation processes [18] and to determine physical properties as vapor pressure and vaporization enthalpy [19].

TG-MS is a powerful hyphenated technique combining the direct measurement of weight loss as a function of temperature with the use of sensitive spectroscopic detectors. Such detectors permit qualitative and quantitative determination of the evolved volatile products to provide kinetic information about the specific reaction mechanisms [20]. Other advantages are speed, reduced sample handling, unique sample, and absence of retention time [21]. Research articles have been published about instrumentation and applications of TG [22-24] and TG-MS $[21,25,26]$.

So, in this work, the objective was to study the lactic acid thermal behavior using DSC, TG/DTG, and TG-MS. The obtained results provided a better understanding of the lactic acid thermal behavior, allowing the development of adequate separation processes.

\section{Experimental}

2.1. Material. DL-lactic acid (molecular weight $90.08 \mathrm{~kg}$. $\mathrm{mol}^{-1}$, CAS number 50-21-5) $~ 90 \%$ standard supplied by Sigma-Aldrich (St Louis, Missouri, EUA) was used in the thermal analysis by DSC, TG/DTG, and TG-MS without prior purification. Water and residual substances are impurities reported by the supplier.
2.2. Differential Scanning Calorimetry. DSC experiment was carried out using Shimadzu equipment (Japan), model DSC50. A dynamic scan was performed at heating rate of $10 \mathrm{~K} \cdot \mathrm{min}^{-1}$ over a temperature range from $294 \mathrm{~K}$ to $773 \mathrm{~K}$. The sample was analyzed under a nitrogen dynamic atmosphere at flow rate of $50 \mathrm{~mL} \mathrm{~min}^{-1}$. The experiments were carried out with a sample size of $\sim 7 \mathrm{mg}$. The samples were weighed into open aluminum pans and hermetically sealed.

2.3. Thermogravimetry. TG experiments were carried out using Shimadzu thermal analyser (Japan), model TGA-50. Constant heating rates of $5,10,15,20,25$, and $30 \mathrm{~K} \cdot \mathrm{min}^{-1}$ were applied. Data were collected in the temperature range from $296 \mathrm{~K}$ to $773 \mathrm{~K}$ under a nitrogen dynamic atmosphere $\left(50 \mathrm{~mL} \cdot \mathrm{min}^{-1}\right)$. The masses of samples were nearly $15 \mathrm{mg}$. The equipment recorded TG and DTG (derivative thermogravimetric analysis) data simultaneously. Data obtained by TG were used to determine evaporation kinetic parameters and evaporation enthalpy. Data obtained by DTG were useful to show the evaporation stages and the effect of heating rate.

2.4. Thermogravimetry Coupled with Mass Spectrometer. TGMS analysis was carried out using Setaram SetSys Evolution 16/18 coupled with a mass spectrometer (MS) Thermostar Pfeiffer Vacuum GSD 301T. MS was responsible for monitoring the masses of compounds that have evolved from the sample during heating. Initially, the sample was heated from $298 \mathrm{~K}$ to $773 \mathrm{~K}$ at heating rate of $10 \mathrm{~K} \cdot \mathrm{min}^{-1}$ under nitrogen atmosphere $\left(16 \mathrm{~mL} \cdot \mathrm{min}^{-1}\right)$ in order to observe the temperature range in which the evolution of mass occurred. Afterwards, the analysis was performed with a mass spectrometer coupled, heating the sample from $293 \mathrm{~K}$ to $573 \mathrm{~K}$ at heating rate of $10 \mathrm{~K} \cdot \mathrm{min}^{-1}$ under nitrogen atmosphere $\left(16 \mathrm{~mL} \cdot \mathrm{min}^{-1}\right)$. In addition, an isothermal at $573 \mathrm{~K}$ was built during $2 \mathrm{~h}$. In this case, a scan of all fragments evolved from the sample during the heating time was used to obtain the thermal and mass spectrum. Finally, TG-MS was performed monitoring fragments of higher intensity. Data were collected and used to obtain the lactic acid thermal behavior and degradation products as a function of temperature and time.

2.5. Kinetic Models. Thermogravimetry is the most common technique used for kinetic analysis. Sample mass variation by temperature data obtained by TG/DTG was used to determine evaporation kinetic parameters. The frequency factor $(A)$ and activation energy $\left(E_{a}\right)$ were obtained using Arrhenius and Kissinger methods.

Calculations are based on the following kinetic equation [18]:

$$
\frac{d \alpha}{d t}=k \times(1-\alpha)^{n}
$$

where $\alpha$ corresponds to the amount of vaporized material, $t$ is the time, $n$ is the apparent reaction order, and $k$ is the rate constant. 
The amount of vaporized material $(\alpha)$ is defined as

$$
\alpha=\frac{m_{0}-m_{t}}{m_{0}-m_{f}}
$$

where $m_{0}$ is the sample initial mass, $m_{t}$ is the sample mass at time $t$, and $m_{f}$ is sample final mass.

$k$ depends on temperature following Arrhenius equation:

$$
k=A \exp \left(-\frac{E_{a}}{R T}\right),
$$

where $A$ is the frequency factor, $E_{a}$ corresponds to the activation energy, and $R$ is the gas constant.

Considering (1) and (3), the following expression is derived:

$$
\frac{d \alpha}{d t}=A \exp \left(-\frac{E_{a}}{R T}\right) \times(1-\alpha)^{n}
$$

2.6. Arrhenius Method. This approach assumes Arrhenius behavior and zero-order reaction kinetics. Taking the natural logarithm in (4), the following expression is derived:

$$
\ln \left(\frac{d \alpha}{d t}\right)=\ln A(1-\alpha)^{n}-\frac{E_{a}}{R T} .
$$

For zero-order reactions $(n=0)$, the equation becomes

$$
\ln \frac{d \alpha}{d t}=\ln A-\frac{E_{a}}{R T}
$$

$d \alpha / d t$ can be calculated by (7). The value of $d m / d t$ is provided by DTG plot.

$$
\frac{d \alpha}{d t}=\frac{-d m / d t}{m_{0}-m_{f}} .
$$

Thus, plotting $\ln (d \alpha / d t)$ versus $(1 / T)$ and correlating the values by the least-square methods to obtain a straight line, the slope will provide the activation energy after being multiplied by $R$. The intercept of this equation will be equivalent to $\ln A$.

2.7. Kissinger Method. Kissinger developed a model-free nonisothermal method where there is no need to calculate $E_{a}$ for each conversion value in order to evaluate kinetic parameters [27]. This method is based on the study of the rate equation at the maximum reaction rate, which means that $d^{2} \alpha / d t^{2}$ is equal to zero. Equation (4) can be written as

$$
\ln \left(\frac{\beta}{T_{m}^{2}}\right)=\ln \left(\frac{A R}{E_{a}}\right)-\frac{E}{R T_{m}},
$$

where $\beta$ is the heating rate $(\beta=d T / d t)$ and $T_{m}$ is the temperature peak of the DTG curve.

The activation energy is determined from the TG data at different heating rates by liner regression of the $\ln \left(\beta / T_{m}^{2}\right)$ versus $T_{m}^{-1}$ plot, and the activation energy $\left(E_{a}\right)$ is calculated from the slope of the resulting straight line.

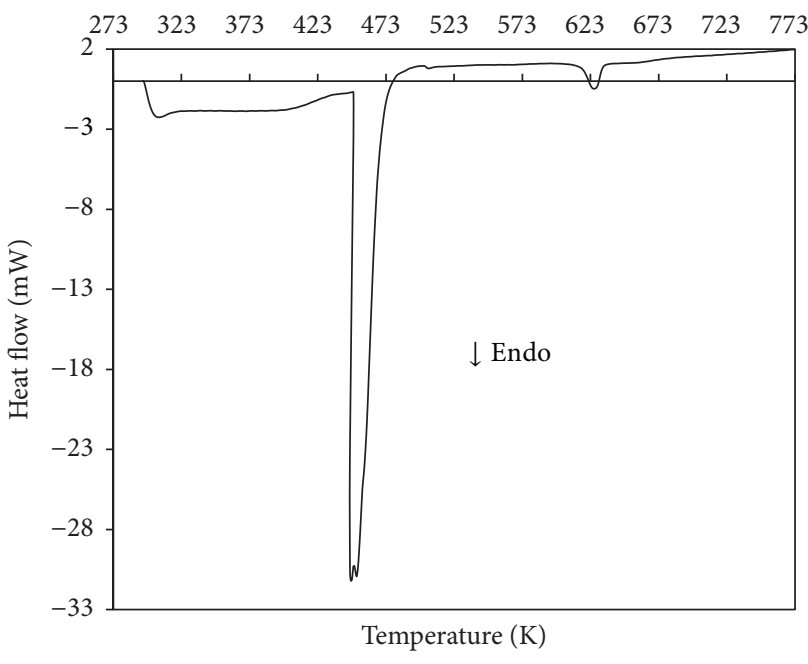

FIGURE 1: DSC lactic acid profile.

2.8. Vaporization Enthalpy. Thermogravimetry is a rapid and convenient technique used for determination of vaporization enthalpy. The theoretical basic of the TG procedure is the Langmuir equation [19]:

$$
\left(\frac{1}{a}\right) \frac{d m}{d t}=p \alpha \sqrt{\frac{M}{2 \pi R T}}
$$

where $d m / d t(a)$ is the rate of mass loss per unit area $\left(\mathrm{kg} \mathrm{s}^{-1} \mathrm{~m}^{-2}\right), p$ is the vapor pressure $(\mathrm{Pa}), M$ is the molecular weight of the vapor of the evaporating compound $\left(\mathrm{kg} \mathrm{mol}^{-1}\right)$, $R$ is the gas constant $\left(\mathrm{J} \mathrm{K}^{-1} \mathrm{~mol}^{-1}\right), T$ is the absolute temperature, and $\alpha$ is the vaporization coefficient.

Rearranging the Langmuir equation gives

$$
p=k v
$$

where $k=\sqrt{2 \pi R} / \alpha$ and $\nu=(1 / a)(d m / d t) \sqrt{T / M}$.

A plot of $\ln v$ against $1 / T$ should give a straight line plot of slope $\Delta H / R$.

\section{Results and Discussion}

3.1. Differential Scanning Calorimetry Analysis. The DSC curve of lactic acid is presented in Figure 1. From this figure, it can be observed that two endothermic peaks are related to the process of lactic acid and lactide evaporation, at $447.35 \mathrm{~K}$ and $625.24 \mathrm{~K}$, respectively. The double small peak in the first peak $(447.35 \mathrm{~K})$ is noted; it probably occurred because of the presence of two isomers $\mathrm{D}(-)$ and $\mathrm{L}(+)$ lactic acid present in the sample.

3.2. Thermogravimetry Analysis. The TG and DTG thermal profiles are shown in Figures 2(a) and 2(b).

The weight loss profile in Figure 2(a) shows the loss of mass with temperature at different heating rates. As can be seen in Figure 2(a), the curves do not show a plateau indicating thermal stability; conversely, evaporation process begins at temperatures around the room temperature and 


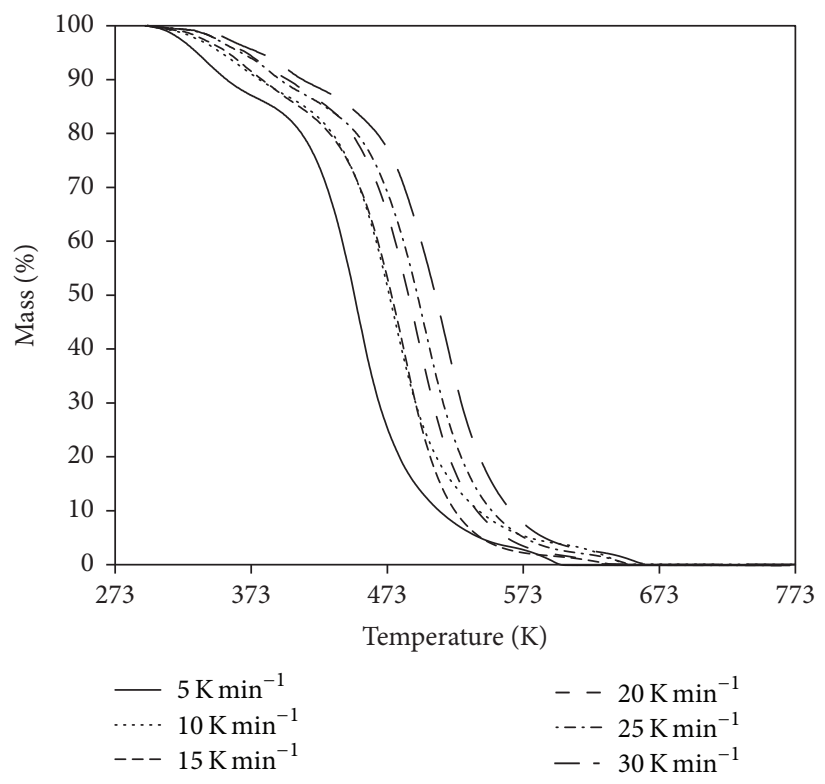

(a)

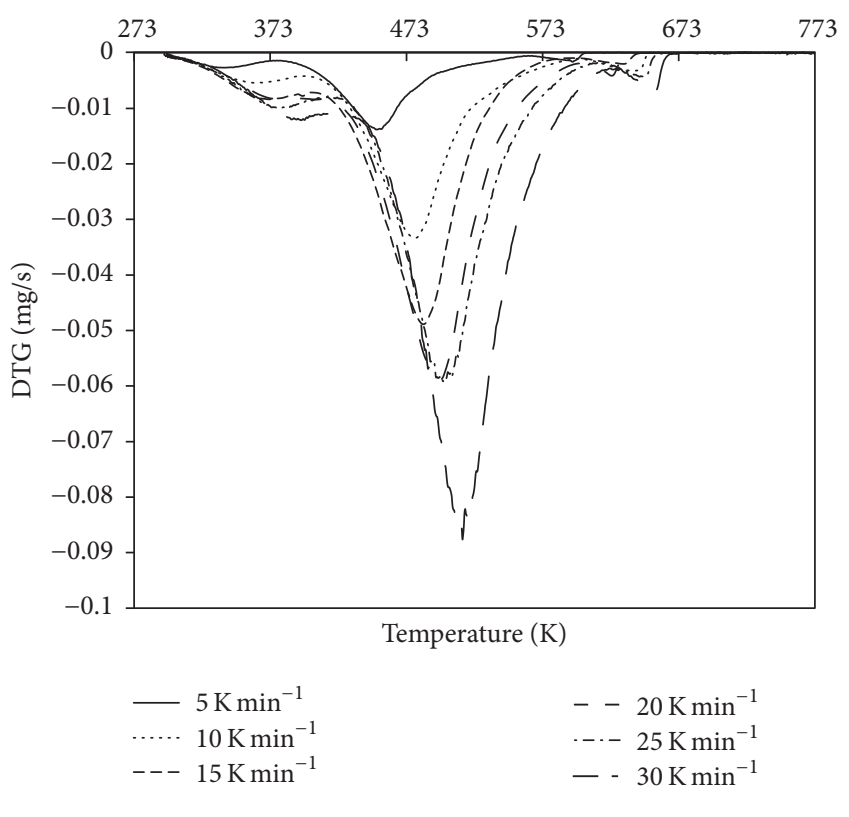

(b)

Figure 2: TG (a) and DTG (b) curves of lactic acid as a function of temperature and heating rates $\left(5,10,15,20,25\right.$, and $\left.30 \mathrm{~K} \cdot \mathrm{min}^{-1}\right)$.

proceeds rapidly with increasing temperature until about $573 \mathrm{~K}$.

The effect of heating rate is shown in Figures 2(a) and 2(b). Heating rates affect TG curve positions and shift maximum temperature peaks $\left(T_{m}\right)$ towards higher temperatures. This phenomenon can be explained on the basis of heat transfer limitation. During the analysis, at low heating rate, a larger instantaneous thermal energy is provided in the system and a longer time may be required for the purge gas to reach equilibrium with the temperature of the furnace or the sample. While at the same time and in the same temperature region, higher heating rate has a short reaction time and the temperature needed for the sample to evaporate is also higher [27].

DTG profiles showed three evaporation stages. The evaporation stages (heating rate of $10 \mathrm{~K} \cdot \mathrm{min}^{-1}$ ) occurred at $\sim 347 \mathrm{~K}, \sim 459 \mathrm{~K}$ and $\sim 612 \mathrm{~K}$ and mass loss percentage of $12.119 \%, 85.520 \%$, and $1.483 \%$, respectively. First was the evaporation of water and methanol impurities $(\sim 347 \mathrm{~K})$ followed by lactic acid $(\sim 459 \mathrm{~K})$ and probably lactide $(\sim 612 \mathrm{~K})$.

The Arrhenius plot for the calculation of activation energy is shown in Figure 3(a). For a reaction to be considered an evaporation process, it is imperative that the mass loss according to the time or temperature should be a zeroorder process [18]. Lactic acid presented in this work showed this behavior, as show in Figure 3(a), using heating rate of $10 \mathrm{~K} \cdot \mathrm{min}^{-1}$. The kinetic parameters determined from TG/ DTG data are shown in Table 1. The advantage of Arrhenius model is the ability to directly determine the kinetic parameters from a single TG measurement.

Kissinger plot of $\ln \left(\beta / T_{m}^{2}\right)$ versus $T_{m}^{-1}$ is shown in Figure 3(b). The kinetic parameters were calculated according to (8) and are given in Table 1 . The advantage of the model-free
TABLE 1: Evaporation kinetic parameters of lactic acid by Arrhenius and Kissinger models.

\begin{tabular}{lcccc}
\hline Model & Heating rate $/ \mathrm{K} \cdot \mathrm{min}^{-1}$ & $\mathrm{Ea} / \mathrm{kJ} \cdot \mathrm{mol}^{-1}$ & $A / \mathrm{s}^{-1}$ & $R^{2}$ \\
\hline Arrhenius & 10 & 51.08 & 859.97 & 0.9962 \\
Kissinger & & 48.37 & 968.81 & 0.9712 \\
\hline
\end{tabular}

analysis is founded on its simplicity and on the avoidance of errors connected with the choice of a kinetic model [27].

The values of activation energy and frequency factor obtained from the Kissinger method are consistent with the values obtained by Arrhenius method (deviation less than $10 \%)$. Kinetic parameters of the lactic acid evaporation process have not been reported in literature review, as described in this work.

The plot of $\ln v$ against $1 / T$ for the calculation of vaporization enthalpy $\left(\Delta H_{\mathrm{vap}}\right)$ is shown in Figure 4 using heating rate of $30 \mathrm{~K} \mathrm{~min}^{-1}$. The vaporization enthalpy calculated was $56.9 \mathrm{~kJ} \mathrm{~mol}^{-1}$. Experimental values for lactic acid vaporization enthalpy are very rare in the literature. Emel'yanenko et al. [28] reported a value of vaporization enthalpy of $69.1 \mathrm{~kJ} \cdot \mathrm{mol}^{-1}$ at $298.15 \mathrm{~K}$ using the transpiration method for the L-lactic acid. Comparing the results, deviations are lower than $18 \%$, which is due to experimental errors and probably the presence of the DL-lactic acid isomer used in this work also influenced the results.

3.3. Thermogravimetry Coupled with Mass Spectrometer Analysis. TG-MS analysis enabled the identification of vaporized molecules and thermal decomposition products from lactic acid at high temperatures. TG-MS profiles are shown in Figure 5. From this figure, it was observed that water $(\mathrm{m} / z=$ 


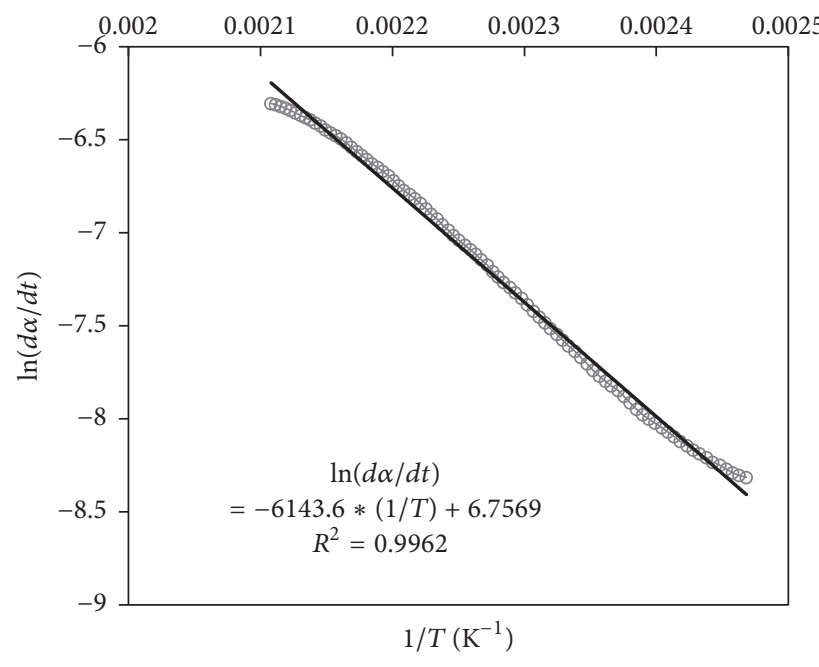

(a)

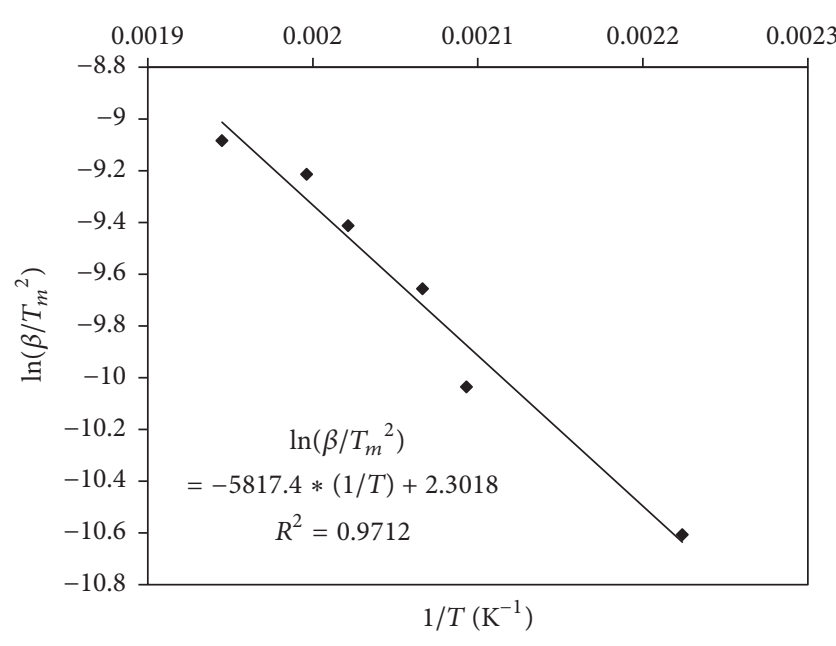

(b)

FIgURE 3: Arrhenius plot (a) and Kissinger plot (b) for the calculation of the activation energy.

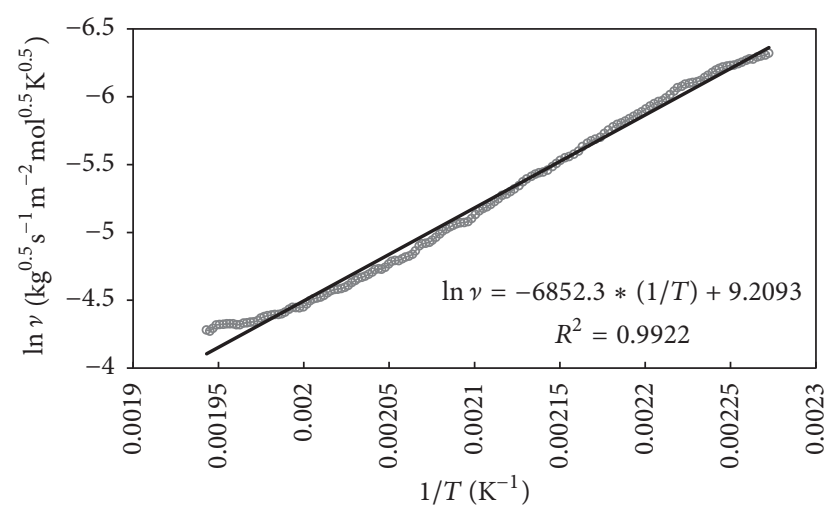

FIGURE 4: The plot of $\ln v$ against $1 / T$ for the calculation of vaporization enthalpy.

18), hydroxyl $(m / z=17)$, and methanol $(m / z=32)$ were the main molecules eliminated during the heating. Water and methanol are impurities from DL-lactic acid commercially produced which has $90 \%$ of purity. Probably, water and methanol come from fermentation and separation processes, respectively. The hydroxyl group probably came from water. Lactide is also an impurity which was observed in DSC curve. The presence of lactide in the commercial lactic acid may be explained due to the tendency of lactic acid to polymerize in concentrated solutions. As described in the literature, above $30 \%$ of lactic acid concentration, the presence of lactide is observed [5]. Other mass fragments monitored during the thermal analysis appeared in low ionic current values.

Lactic acid can be conveniently converted into various value-added products, such as acrylic acid. For acrylic acid production, direct dehydration of lactic acid in high temperatures is an alternative. For better understanding the lactic acid thermal behavior at high temperatures, TG-MS isotherm of lactic acid at $573 \mathrm{~K}$ was performed as shown in Figure 6. The isotherm profiles were divided into parts (a) and (b) for better visualization.

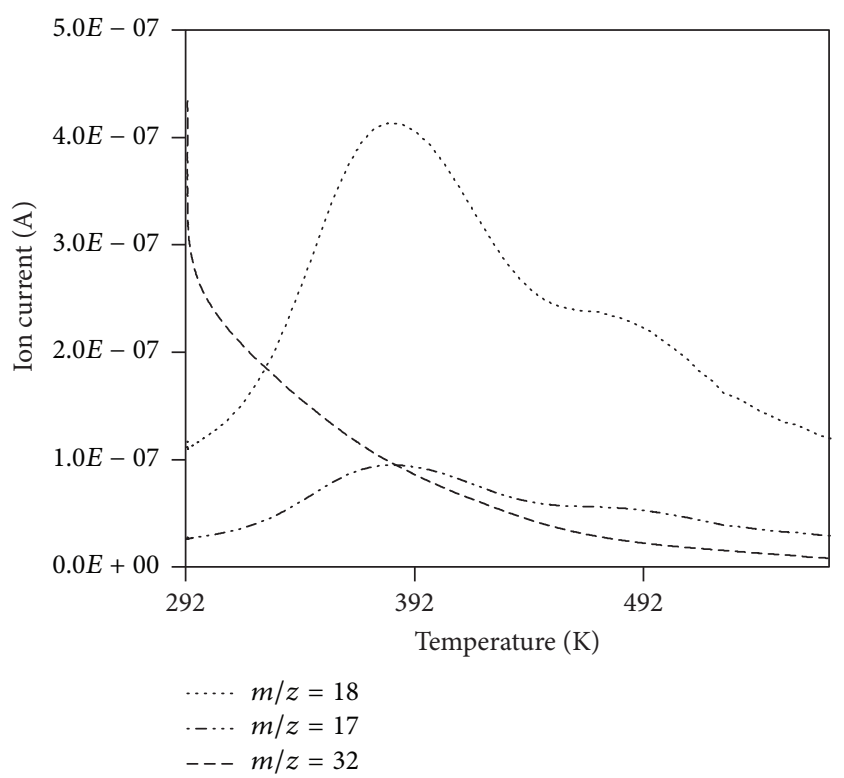

FIgURE 5: TG-MS profiles of lactic acid.

Figure 6 showed the fragments products of hydroxyl $(m / z=17)$, water $(m / z=18)$, methanol $(m / z=32)$, acetaldehyde or/and carbon dioxide $(m / z=44)$, formate $(m / z=45)$, acrylic acid $(m / z=72)$, and propionic acid $(m / z=74)$. It can be concluded that various reactions occurred concurrently. At approximately 30 min of heating, the presence of dehydration reactions (11) as well as reduction (12) and decarboxylation reactions (13) was observed.

$$
\mathrm{C}_{3} \mathrm{H}_{6} \mathrm{O}_{3} \longrightarrow \mathrm{C}_{3} \mathrm{H}_{4} \mathrm{O}_{2}+\mathrm{H}_{2} \mathrm{O}
$$

Lactic acid $\longrightarrow$ acrylic acid + water

$$
\mathrm{C}_{3} \mathrm{H}_{6} \mathrm{O}_{3} \longrightarrow \mathrm{C}_{3} \mathrm{H}_{6} \mathrm{O}_{2}+\frac{1}{2} \mathrm{O}_{2}
$$

Lactic acid $\longrightarrow$ propionic acid + oxygen 


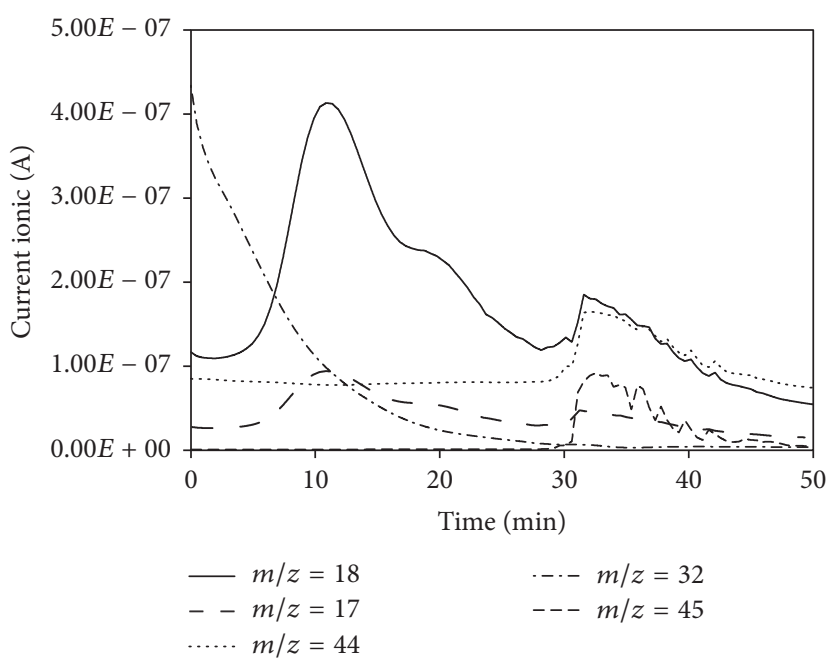

(a)

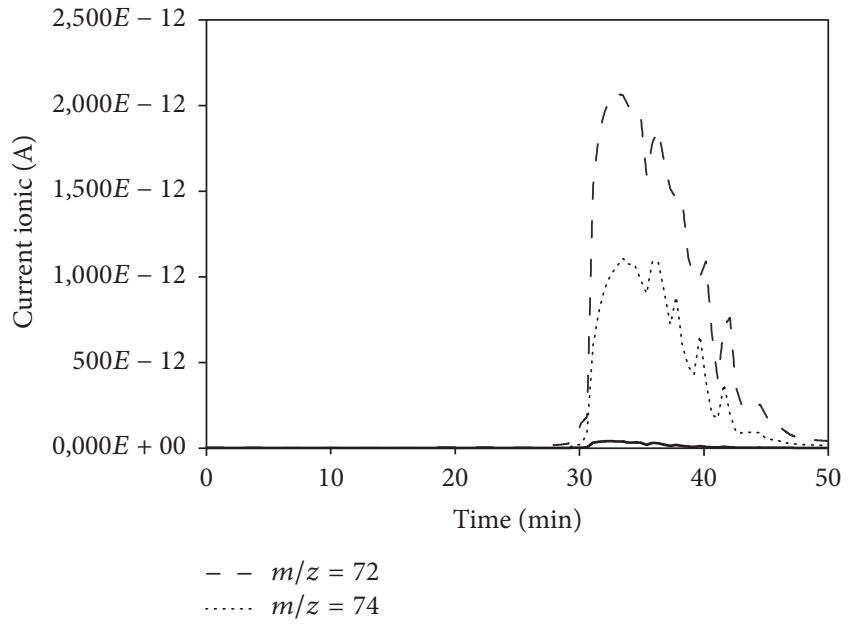

(b)

Figure 6: TG-MS lactic acid isothermal at $573 \mathrm{~K}$ during the time. (a): $m / z=17,18,32,44$, and 45 . (b): $m / z=72$ and 74 . The solid line in (b) is a type of noise from the equipment.

$$
\mathrm{C}_{3} \mathrm{H}_{6} \mathrm{O}_{3} \longrightarrow \mathrm{C}_{2} \mathrm{H}_{4} \mathrm{O}+\mathrm{CO}_{2}+\mathrm{H}_{2}
$$

Lactic acid $\longrightarrow$ acetaldehyde + carbon dioxide + hydrogen

According to the literature, the formation of self-reaction products such as lactide, which are subsequently more readily decomposed into fragments (e.g., carbon monoxide, acetaldehyde, and water), is the main reaction that competes with the dehydration process [29]. Data obtained from TGMS are in agreement with the literature.

Additionally, at the end of the analysis, the sample was found graphitized indicating that a quantity of the sample was reduced, also confirming the analysis of the mass profiles. It can be concluded that the decomposition process of lactic acid is related to temperature and the time of exposure to heat. In addition, only after $30 \mathrm{~min}$ of heating at $573 \mathrm{~K}$ lactic acid was decomposed into water, hydroxyl, methanol, acetaldehyde or/and carbon dioxide, formate, acrylic acid, and propionic acid as can be seen by increasing the current ionic at $30 \mathrm{~min}$.

Therefore, it is important work with separation processes, which minimize problems of thermal decomposition to avoid the formation of byproducts. Vacuum operations provide a substantial decrease in the boiling points of substances due to operating pressure reduction. This characteristic allows the separation of compounds that would be destroyed if the mixture is processed at normal pressures [30]. This characteristic is satisfied by the hybrid short path evaporation. It has been recognized as a promising technology mainly because of its low evaporation temperature and short residence time [31].

\section{Conclusions}

In this work, thermal characterization of lactic acid using thermoanalytical techniques was presented. DSC analyses showed endothermic peaks related to the process of evaporation. Effect of heating rate on TG and DTG curves was also presented and the data were correlated to Arrhenius and Kissinger equations to provide the evaporation kinetic parameters. Activation energies were 51.08 and $48.37 \mathrm{~kJ} \cdot \mathrm{mol}^{-1}$ and frequency values were 859.97 and $968.81 \mathrm{~s}^{-1}$ obtained by Arrhenius and Kissinger equations, respectively. Enthalpy of vaporization calculated by TG was $56.9 \mathrm{~kJ} \cdot \mathrm{mol}^{-1}$. TG-MS curve profiles showed many decomposition products when lactic acid was heated at $573 \mathrm{~K}$ in approximately $30 \mathrm{~min}$. It can be concluded that decomposition process of lactic acid is related to temperature and the time of exposure to heat. Therefore, separation and purification processes which work with vacuum and short residence time are favored.

\section{Conflicts of Interest}

The authors declare that they have no conflicts of interest.

\section{Acknowledgments}

The authors are acknowledging the financial support from São Paulo Research Foundation (FAPESP) (Project nos. 2012/ 17501-0 and 2015/12783-5).

\section{References}

[1] Y.-J. Wee, J.-N. Kim, and H.-W. Ryu, Food Technology and Biotechnology, vol. 44, pp. 163-172, 2006.

[2] R. Datta and M. Henry, Journal of Chemical Technology and Biotechnology, vol. 81, pp. 1119-1129, 2006.

[3] A. Komesu, P. F. Martins, B. H. Lunelli et al., "Lactic acid purification by hybrid short path evaporation," Chemical Engineering Transactions, vol. 32, pp. 2017-2022, 2013.

[4] L. Chen, A. Zeng, H. Dong, Q. Li, and C. Niu, "A novel process for recovery and refining of l-lactic acid from fermentation broth," Bioresource Technology, vol. 112, pp. 280-284, 2012. 
[5] B. H. Lunelli, Production and control of the acrylic acid ester synthesis through lactic acid fermentation [Ph.D. thesis], University of Campinas, Sao paulo, Brazil, 2010.

[6] E. Fortunati, I. Armentano, A. Iannoni, and J. M. Kenny, "Development and thermal behaviour of ternary PLA matrix composites," Polymer Degradation and Stability, vol. 95, no. 11, pp. 2200-2206, 2010.

[7] V. S. Giita Silverajah, N. A. Ibrahim, N. Zainuddin, W. M. Z. Wan Yunus, and H. A. Hassan, "Mechanical, thermal and morphological properties of poly(lactic acid)/epoxidized palm olein blend," Molecules, vol. 17, no. 10, pp. 11729-11747, 2012.

[8] V. Speranza, A. De Meo, and R. Pantani, “Thermal and hydrolytic degradation kinetics of PLA in the molten state," Polymer Degradation and Stability, vol. 100, no. 1, pp. 37-41, 2014.

[9] S.-L. Yang, Z.-H. Wu, W. Yang, and M.-B. Yang, “Thermal and mechanical properties of chemical crosslinked polylactide (PLA)," Polymer Testing, vol. 27, no. 8, pp. 957-963, 2008.

[10] S. Solarski, M. Ferreira, and E. Devaux, "Characterization of the thermal properties of PLA fibers by modulated differential scanning calorimetry," Polymer, vol. 46, no. 25, pp. 11187-11192, 2005.

[11] C. S. López-Garzón and A. J. J. Straathof, "Recovery of carboxylic acids produced by fermentation," Biotechnology Advances, vol. 32, no. 5, pp. 873-904, 2014.

[12] M. G. Ionashiro, Fundamentos da Termogravimetria e Análise Térmica Diferencial e Calorimetria Exploratória Diferencial, Giz Editorial, São Paulo, Brazil, 2005.

[13] K. V. Kodre, S. R. Attarde, P. R. Yendhe, R. Y. Patil, and V. U. Barge, "Differential Scanning Calorimetry: A Review," Research and Reviews: Journal of Pharmaceutical Analysis, vol. 3, pp. 1122, 2014.

[14] S.-D. Clas, C. R. Dalton, and B. C. Hancock, "Differential scanning calorimetry: applications in drug development," Pharmaceutical Science and Technology Today, vol. 2, no. 8, pp. 311320, 1999.

[15] B. Z. Chowdhry and S. C. Cole, "Differential scanning calorimetry: applications in biotechnology," Trends in Biotechnology, vol. 7, no. 1, pp. 11-18, 1989.

[16] C. G. Biliaderis, "Differential scanning calorimetry in food research: a review," Food Chemistry, vol. 10, no. 4, pp. 239-265, 1983.

[17] L. Dai, L.-Y. Wang, T.-Q. Yuan, and J. He, "Study on thermal degradation kinetics of cellulose-graft-poly(l-lactic acid) by thermogravimetric analysis," Polymer Degradation and Stability, vol. 99, no. 1, pp. 233-239, 2014.

[18] P. F. Martins, P. Sbaite, C. I. Benites, M. R. Wolf Maciel, and R. Maciel Filho, in AIDIC Conference Series, vol. 10, pp. 233-242, 2011.

[19] S. F. Wright, D. Dollimore, J. G. Dunn, and K. Alexander, "Determination of the vapor pressure curves of adipic acid and triethanolamine using thermogravimetric analysis," Thermochimica Acta, vol. 421, no. 1-2, pp. 25-30, 2004.

[20] W. H. McClennen, R. M. Buchanan, N. S. Arnold, J. P. Dworzanski, and H. L. C. Meuzelaar, "Thermogravimetry/gas chromatography/mass spectrometry and thermogravimetry/gas chromatography/Fourier transform infrared spectroscopy: novel hyphenated methods in thermal analysis," Analytical Chemistry, vol. 65, no. 20, pp. 2819-2823, 1993.

[21] K. G. H. Raemaekers and J. C. J. Bart, "Applications of simultaneous thermogravimetry-mass spectrometry in polymer analysis," Thermochimica Acta, vol. 295, no. 1-2, pp. 1-58, 1997.
[22] W. Pu, S. Pang, and H. Jia, "Using DSC/TG/DTA techniques to re-evaluate the effect of clays on crude oil oxidation kinetics," Journal of Petroleum Science and Engineering, vol. 134, pp. 123130,2015

[23] S. N. Monteiro, V. Calado, F. M. Margem, and R. J. S. Rodriguez, "Thermogravimetric stability behavior of less common lignocellulosic fibers: a review," Journal of Materials Research and Technology, vol. 1, no. 3, pp. 189-199, 2012.

[24] A. W. Coats and J. P. Redfern, "Thermogravimetric analysis. a review," The Analyst, vol. 88, no. 1053, pp. 906-924, 1963.

[25] S. Materazzi and R. Risoluti, "Evolved gas analysis by mass spectrometry," Applied Spectroscopy Reviews, vol. 49, no. 8, pp. 635-665, 2014.

[26] B. Roduit, J. Baldyga, M. Maciejewski, and A. Baiker, "Influence of mass transfer on interaction between thermoanalytical and mass spectrometric curves measured in combined thermoanalyser-mass spectrometer systems," Thermochimica Acta, vol. 295, no. 1-2, pp. 59-71, 1997.

[27] K. Slopiecka, P. Bartocci, and F. Fantozzi, "Energy solutions for a sustainable world," in Proceedings of the 3rd International Conference on Applied Energy, pp. 1687-1698, Perugia, Italy, 2011.

[28] V. N. Emel'yanenko, S. P. Verevkin, C. Schick, E. N. Stepurko, G. N. Roganov, and M. K. Georgieva, "The thermodynamic properties of S-lactic acid," Russian Journal of Physical Chemistry A, vol. 84, no. 9, pp. 1491-1497, 2010.

[29] X. Xu, J. Lin, and P. Cen, "Advances in the research and development of acrylic acid production from biomass," Chinese Journal of Chemical Engineering, vol. 14, no. 4, pp. 419-427, 2006.

[30] P. F. Martins, C. Carmona, E. L. Martinez, P. Sbaite, R. MacIel Filho, and M. R. Wolf MacIel, "Short path evaporation for methyl chavicol enrichment from basil essential oil," Separation and Purification Technology, vol. 87, pp. 71-78, 2012.

[31] A. Komesu, P. F. Martins, B. H. Lunelli, J. Oliveira, R. Maciel Filho, and M. R. Wolf Maciel, "Evaluation of lactic acid purification from fermentation broth by hybrid short path evaporation using factorial experimental design," Separation and Purification Technology, vol. 136, pp. 233-240, 2014. 

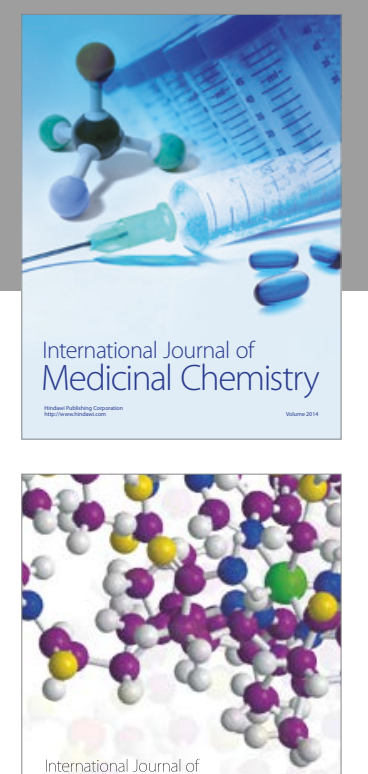

Carbohydrate Chemistry

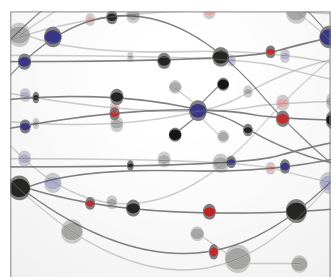

The Scientific World Journal
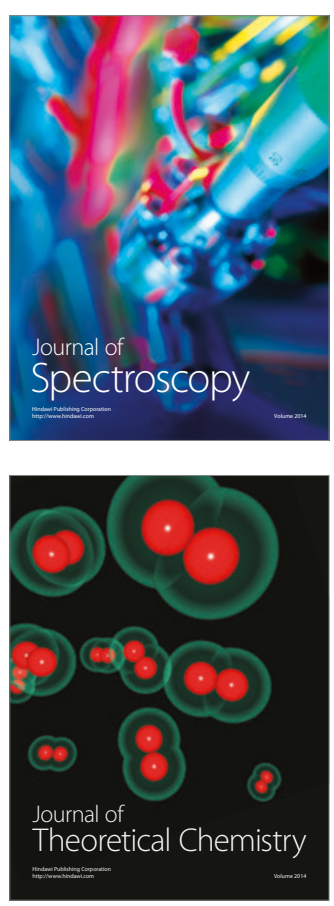
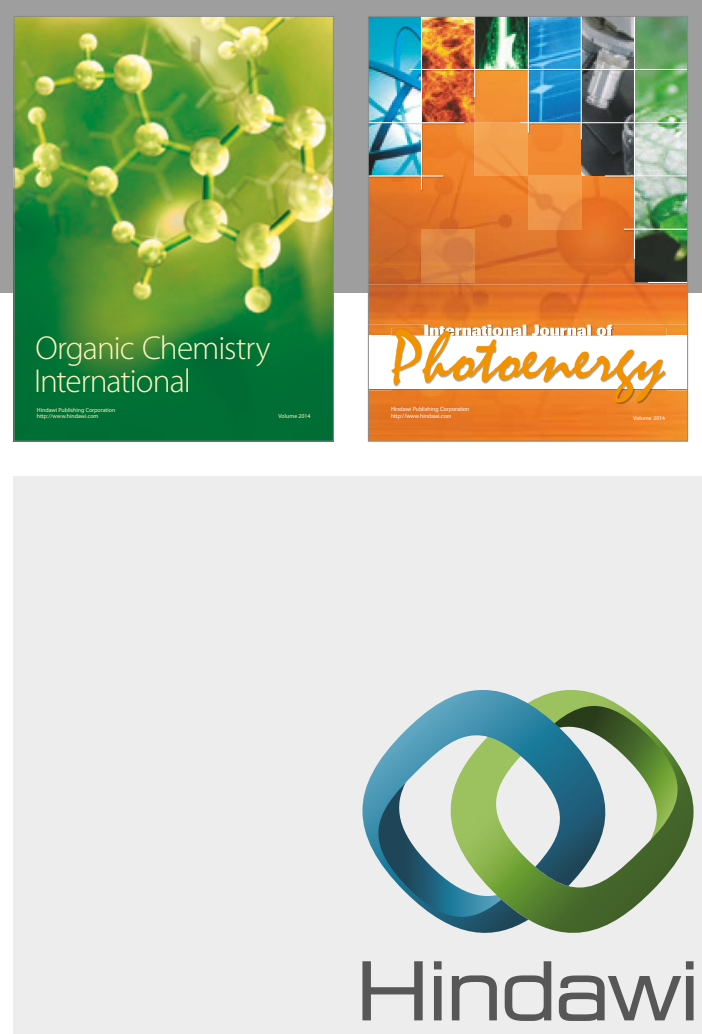

Submit your manuscripts at

https://www.hindawi.com

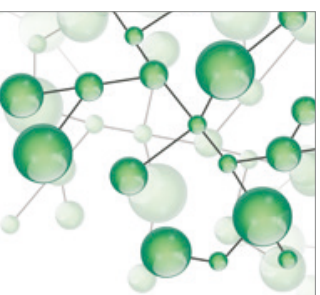

International Journal of

Inorganic Chemistry

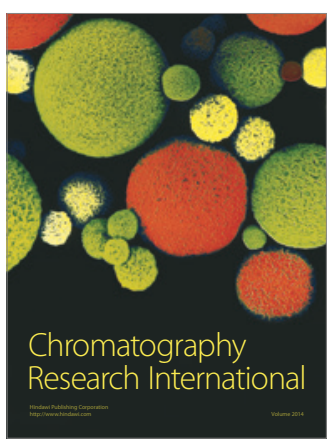

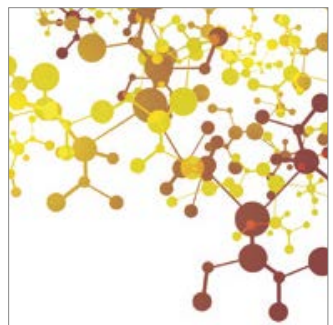

Applied Chemistry
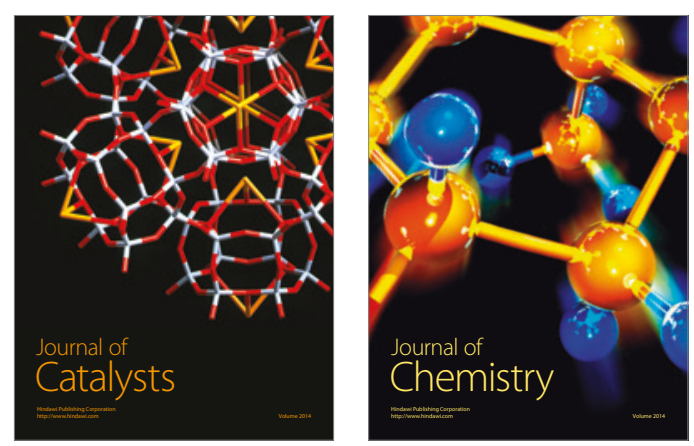
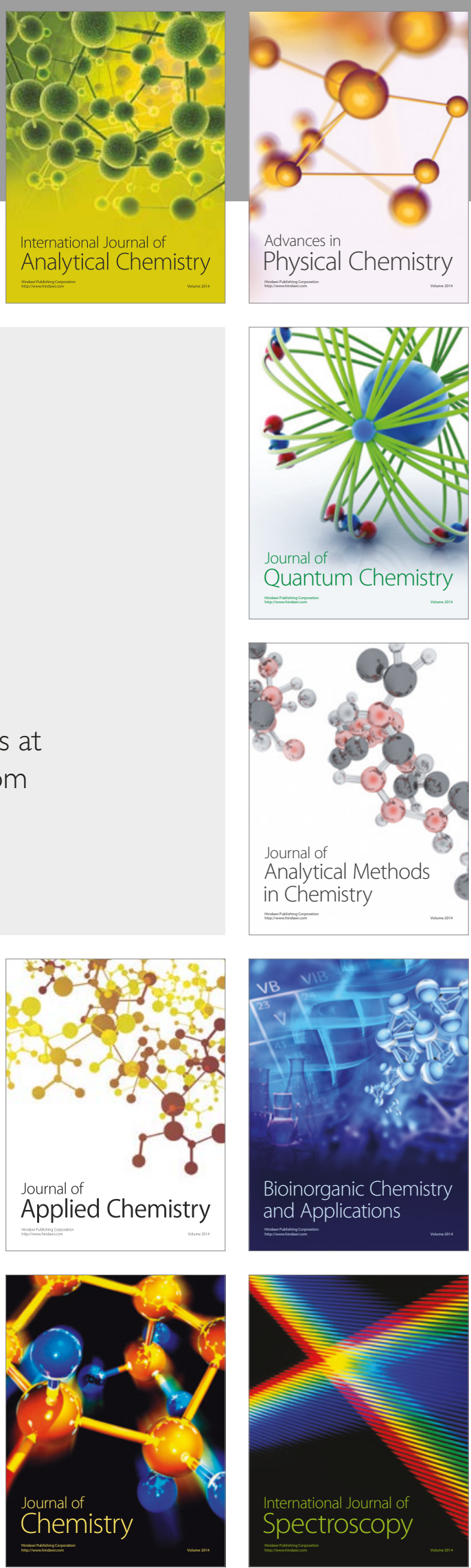